\title{
Negative priming and stimulus familiarity: What causes opposite results?
}

\author{
JUN-ICHI NAGAI and KAZUHIKO YOKOSAWA \\ University of Tokyo, Tokyo, Japan
}

\begin{abstract}
There has been a discrepancy among past studies with regard to the relation between negative priming and familiarity of stimuli. That is, Malley and Strayer (1995; Strayer \& Grison, 1999) reported that the more familiar the stimuli were, the larger negative priming became (i.e., a positive correlation), whereas DeSchepper and Treisman (1996; Treisman \& DeSchepper, 1996) reported that the less familiar the stimuli were, the larger negative priming became (i.e., a negative correlation). These studies differ not only in their experimental tasks (identification vs. matching) but also in their respective manners of arranging unfamiliar stimuli (pure vs. mixed). In the present study, using an identical set of stimuli, we examined whether these factors caused the opposite results. An identification task with a pure arrangement produced a positive correlation, and a matching task with a mixed arrangement produced a negative correlation. These results suggest that the past opposing results are both replicable and that they have reflected the different causal mechanisms of negative priming.
\end{abstract}

Regarding the relation between negative priming (Dalrymple-Alford \& Budayr, 1966; Neill, 1977; Tipper, 1985) and stimulus familiarity, the results of past studies have been discrepant in that Malley and Strayer (1995; Strayer \& Grison, 1999; see also Grison \& Strayer, 2001) reported a positive correlation between them whereas DeSchepper and Treisman (1996; see also Treisman \& DeSchepper, 1996) reported a negative correlation. The purpose of the present article was to examine differences between these studies and then to present new evidence to suggest what caused these researchers to obtain opposite results.

In the experimental paradigm of negative priming formalized by Tipper (1985), participants are required to respond selectively to a target stimulus while ignoring a distractor stimulus on every trial. What is crucial here is the relation between the targets and the distractors of two successive trials (the former is called the prime; the latter is called the probe). In the baseline condition, or control, no relation exists between the targets and the distractors of the prime and probe trials. On the other hand, in the experimental condition, or ignored repetition, the distractor stimulus ignored on the prime trial is presented as the target stimulus on the probe trial. In general, responses to

This study was supported by Grant-in-Aid for Scientific Research (B) 11410024, awarded to K.Y. by the Japan Society for the Promotion of Science. We are indebted to Yohtaro Takano for his warm support at the early stages of this study, and to Ewald Neumann and David Strayer for their very helpful comments on earlier versions of this article. Portions of this study were reported at the annual meeting of the Association for Research in Vision and Ophthalmology, April 2000, Ft. Lauderdale, Florida. Correspondence should be addressed to J. Nagai, Department of Cognitive and Behavioral Science, Graduate School of Arts and Sciences, University of Tokyo, Komaba, Meguro-ku, Tokyo 153-0041, Japan (e-mail: jnagai@ muc.biglobe.ne.jp). the probe target in the ignored-repetition condition are slower than those in the control condition. This delay effect is referred to as negative priming, which has been reported with a variety of tasks and a variety of stimuli (for reviews, see Fox, 1995; May, Kane, \& Hasher, 1995; Neill, Valdes, \& Terry, 1995; Tipper, 2001).

According to Malley and Strayer (1995; Strayer \& Grison, 1999), stimulus repetition is necessary for the occurrence of negative priming. In the word identification (naming) task of Malley and Strayer, negative priming failed to occur in response to novel words that were presented only twice as the prime distractor and the probe target (Experiments 1 and 2), whereas words that were used repeatedly throughout the experiment produced negative priming (Experiments 3 and 4). Even when the familiarity of words (novel/repeated) was manipulated as a withinsubjects variable (Experiment 5; Strayer \& Grison, 1999, Experiments 1 and 2), these results were replicated. That is, the results of Malley and Strayer showed that the more familiar stimuli were, the larger negative priming became (i.e., a positive correlation).

On the basis of these results, Malley and Strayer (1995; Strayer \& Grison, 1999) developed an "activation" hypothesis of negative priming. In this hypothesis, it is assumed that repeated presentation of stimuli increases the level of activation of their representations that have been stored preexperimentally. When the representations of the distractors are activated enough to cause interference with selecting and responding to the targets, the inhibitory mechanisms of attention work reactively and result in the emergence of negative priming (if the preceding distractors become subsequent targets). The activation hypothesis is a variety of the distractorinhibition theories of negative priming (e.g., Houghton \& Tipper, 1994; Neill, 1977; Neumann \& DeSchepper, 1992; 
Tipper, 1985) in that it postulates inhibitory mechanisms of attention that are associated with the preexisting representations of the distractor stimuli.

On the other hand, according to DeSchepper and Treisman (1996, Experiment 2; Treisman \& DeSchepper, 1996, Experiment 1), novel stimuli produced larger negative priming than did repeated stimuli. In the same-different matching task of DeSchepper and Treisman (1996; Treisman \& DeSchepper, 1996), nonsense shapes were employed as stimuli and their repetition was manipulated in the same manner as in the experiments of Malley and Strayer (1995). However, negative priming did occur in response to even novel shapes that appeared only twice, and the effect was significantly larger than that produced by repeatedly used shapes. That is, the results of DeSchepper and Treisman (1996; Treisman \& DeSchepper, 1996) showed that the less familiar stimuli were, the larger negative priming became (i.e., a negative correlation).

The results of DeSchepper and Treisman (1996; Treisman \& DeSchepper, 1996) can be interpreted as evidence for the episodic retrieval theory of negative priming (Neill, Valdes, Terry, \& Gorfein, 1992), rather than for the distractor inhibition theories. The distractor inhibition theories suggest that if novel nonsense shapes are presented as the distractors, negative priming should fail to occur because there are no preexisting representations of the distractors to be inhibited. The occurrence of negative priming in response to novel nonsense shapes suggests that negative priming depends not upon the preexisting representations of the distractors but upon their episodic representations, created each time they appear. According to the episodic retrieval theory, the episodic representation of a previous distractor (the "do not respond" tag) will be automatically retrieved when it matches a current target, and it will then produce conflict with responding to the current target because its previous status differs from the current requirements. This conflict is considered to be the cause of negative priming (DeSchepper \& Treisman, 1996; Neill et al., 1992).

The discrepancy between the results of Malley and Strayer (1995; Strayer \& Grison, 1999; Grison \& Strayer, 2001) and DeSchepper and Treisman (1996; Treisman \& DeSchepper, 1996) is important not merely phenomenally but also theoretically. One likely cause of these researchers' opposite results is the difference in task requirement: Malley and Strayer (1995; Strayer \& Grison, 1999, Experiments 1 and 2) required their participants to identify words, whereas DeSchepper and Treisman (1996; Treisman \& DeSchepper, 1996) required theirs to match nonsense shapes. We believe that the difference in tasks was important, because participants' behavioral goals were different as a result of the differing tasks to be performed. According to Tipper, Weaver, and Houghton (1994; Milliken, Tipper, \& Weaver, 1994), negative priming is dependent upon the behavioral goals (e.g., identity, color, or location), even though the visual displays for selection were identical. The results of Tipper et al. indicate that negative priming is associated with only those representations that are relevant to the current be- havioral goal. There is a possibility that the difference in task-relevant representations between the identification and the matching tasks caused the positive correlation in the identification task and the negative correlation in the matching task.

In Experiment 4 of Strayer and Grison (1999), however, a positive correlation was obtained even in the shapematching task with both familiar and nonsense shapes. In this experiment, only 10 shapes were repeatedly presented in each block of 128 trials. Then each block was divided into quartiles, and the effect of within-block stimulus repetition was examined. Whereas negative priming was not obtained in the first quartile, it became reliable in the second, third, and fourth quartiles. That is, in line with the results of Malley and Strayer (1995), the results showed a positive correlation between negative priming and stimulus familiarity. Furthermore, in Strayer and Grison's Experiment 5 , negative priming was not obtained in the matching task with novel nonsense shapes, in which all shapes were presented only once or twice. Why Strayer and Grison failed to reproduce the results of DeSchepper and Treisman (1996; Treisman \& DeSchepper, 1996) remains an unsolved problem.

Given such puzzling circumstances, in the present study we focused on the difference between the identification and the matching tasks on the basis of the behavioral goal hypothesis of Tipper et al. (1994). Following their methodology, we examined the influence of task difference directly using identical stimulus displays. For this purpose, we developed a new type of stimulus display, as illustrated in Figure 1A. In each trial, two sameidentity targets and two same-identity distractors were presented, and in half the trials, one of the targets was presented in its mirror image. Two types of task requirement, identification and matching, were applied to these identical stimulus displays. The identification task required identifying the targets, and the matching task required deciding whether the two targets had the same image (i.e., one was presented in the mirror image). Because the two targets had the same identity regardless of whether one was mirror imaged, the same-different matching task should be performed by means of shape representations rather than identity ones. If the difference of relevant representations between the identification and the matching tasks was critical, we would obtain opposite results between the two tasks regarding the correlation between negative priming and stimulus familiarity.

The familiar and unfamiliar stimulus sets used in the present study are illustrated in Figure 1B. The familiar stimuli were created as digits, and the unfamiliar ones were their respective deformations. Whereas familiarity was operationally defined by stimulus repetition in the past studies, we defined it on the basis of familiarity of shapes. Although there are a variety of ways to manipulate the concept of familiarity, it is unclear whether these operations are compatible with one another. Unlike the past studies, the present study used a limited number of stimuli repeatedly in both conditions (high/low) of familiarity. The results yielded new evidence of the effects 


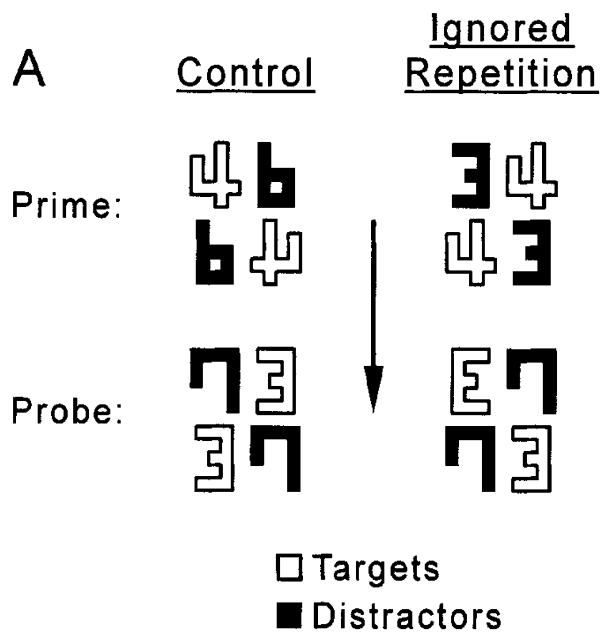

B
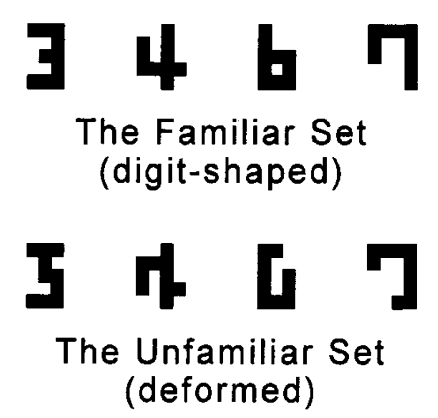

Figure 1. (A) Examples of control and ignored-repetition trials in the high-familiarity condition. Although targets are shown here as unfilled forms and distractors as filled ones, they were actually presented in their assigned colors. (B) The eight visual forms used as stimuli. The four forms of the familiar set were shaped as digits; the four of the unfamiliar set were respective deformations of those of the familiar set.

of stimulus familiarity on negative priming independent of stimulus repetition.

\section{EXPERIMENT 1A Identification Task}

In Experiment 1A, we examined whether the familiar stimuli would produce larger negative priming than the unfamiliar stimuli in the identification task.

\section{Method}

Participants. Twenty-four native Japanese students (6 women and 18 men, between 18 and 23 years old) were tested. None of them took part in other experiments of the present study. All participants reported normal or corrected-to-normal visual acuity and normal color vision.

Stimuli and Apparatus. The stimuli were eight visual forms consisting of 10 squares (see Figure 1B). Four of them were shaped like the digits $3,4,6$, and 7 (the familiar set), and the other four were their respective deformations with an arbitrary shift of one square (the unfamiliar set). They were displayed in green or red (system palette numbers 2 and 4 ) on a dark background of a 17-in. CRT monitor. The targets and the distractors were differentiated by the assignment of color, which was counterbalanced across partic- ipants. Each form subtended approximately $0.7^{\circ} \times 0.5^{\circ}$ from a viewing distance of $57 \mathrm{~cm}$.

In each trial, four forms (two targets and two distractors) were presented simultaneously as a $2 \times 2$ matrix (see Figure $1 \mathrm{~A}$ ). The centers of each form were positioned at the corners of an imaginary rectangle, which subtended approximately $1.0^{\circ} \times 0.8^{\circ}$. The two forms at diagonally opposite corners were the same in color and shape. The targets' diagonal was chosen randomly on every prime trial, and it was another diagonal on the following probe trial. To use the same stimulus displays in the matching task, in half of the trials one of the target forms was presented in its mirror image (the corner was chosen at random). Trial events and data collection were controlled by an NEC PC-9821 computer.

Task. The task was the identification of the target forms by means of a four-alternative forced choice. For each participant, the four numbers $(3,4,6$, and 7) were randomly assigned to four keys (D, C, M, and K). The participants were told that the stimuli were shaped as the digits $(3,4,6$, and 7$)$ or their respective deformations, and then asked to make a key response that corresponded to the targets, while ignoring the distractors. As for the deformed version, the participants were instructed to judge which of the four digits was the original form of the targets. Answering speed and accuracy were equally emphasized.

Design. A $2 \times 2$ mixed design was used. The between-subjects variable was stimulus familiarity (high, low), which was manipulated by arrangement of the forms. In the high-familiarity condition, the forms were always chosen from the familiar set; in the lowfamiliarity condition, they were from the unfamiliar set. On the other hand, the within-subjects variable was trial type (ignored repetition, control), which was defined by the relation between the prime and probe trials (odd-numbered and even-numbered trials, respectively). Ignored-repetiti on trials were those in which the prime distractors reappeared as the probe targets and no other forms were in common between the two trials. Control trials were those in which the two trials shared no common forms. Examples of the two trial types in the high-familiarity condition are schematically illustrated in Figure 1A.

Procedure. The participants were tested individually in a single session lasting about $30 \mathrm{~min}$. After receiving instructions about the task, each participant completed the practice phase, which consisted of three blocks of 24 trials. The choice of targets and distractors was random in each practice trial, with the restriction that each form appeared equally often both as a target and as a distractor. The displays containing the mirror-image targets (the different displays) appeared as many times as the displays not containing them (the same displays). The data from the practice phase were not collected.

Next, each participant completed the test phase, which consisted of six blocks of 64 trials ( 32 prime-probe pairs). Within each block of the test phase, an equal number of ignored-repetition and control trials was presented in a random order, with the same restriction as in the practice phase. Moreover, each of same-same, same-different, different-same, and different-different sequences of the prime-probe displays appeared with equal frequency within each condition of the trial type. ${ }^{1}$ Both in the practice phase and in the test phase, the participants took a 10 -sec rest after completing each block. During this rest period, mean response time (RT) and percentage of correct trials from the previous block were displayed on the monitor. In the test phase, if errors were over $5 \%$ on a given block, a message to "be careful and reduce your errors" (in Japanese) was displayed. After the rest period, the participants initiated the next block by pressing the space bar when they were ready to continue.

Each trial began with the presentation of a white fixation plus $\left(0.2^{\circ} \times 0.2^{\circ}\right)$ for $250 \mathrm{msec}$ at the center of the monitor, followed by a blank screen for $100 \mathrm{msec}$. Then the $2 \times 2$ matrix of the forms was presented at the center of the monitor and remained in view until the participant's first response. After the presentation of a 150 -msec blank screen following the offset of the stimuli, the fixa- 
tion plus of the next trial appeared. If an erroneous response was made, a beep was presented during the 150 -msec blank, and then a 2,000-msec interruption was added before the next fixation.

\section{Results and Discussion}

If there was an error response within a prime-probe trial pair, the data concerning that pair were excluded from the analyses of RT. For each combination of independent variables $(2 \times 2)$, median RTs of the prime and probe trials and an error rate (ER) were calculated. The ERs were percentages of all prime-probe pairs where an error response was made on the prime trial, the probe trial, or both (i.e., percentages of the excluded pairs). Throughout the present study, an alpha level of .05 was used for all of the tests.

Negative priming. Mean median probe RTs and ERs are shown in Table 1. A 2 (familiarity: high, low) $\times 2$ (trial type: ignored repetition, control) mixed analysis of variance (ANOVA) was conducted on the probe RTs. The main effect of trial type $\left[F(1,22)=7.59, M S_{\mathrm{e}}=\right.$ $1,656, p<.05]$ and the interaction $\left[F(1,22)=4.50, M S_{\mathrm{e}}=\right.$ $981, p<.05]$ were significant, but the main effect of familiarity was not $\left[F(1,22)=3.31, M S_{\mathrm{e}}=17,787, p>.08\right]$. The significance of the interaction suggests that negative priming depended on stimulus familiarity. Panel A of Figure 2 shows the negative priming obtained in Experiment $1 \mathrm{~A}$. Individual tests of simple main effects confirmed that significant negative priming occurred in the high-familiarity condition $(21 \mathrm{msec})[F(1,22)=11.89$, $p<.01]$, but not in the low-familiarity condition $(2 \mathrm{msec})$ $[F(1,22)=0.20]$. These results indicate that larger negative priming was obtained in the high-familiarity condition. The same $2 \times 2$ mixed ANOVAs conducted on the prime RTs and the arcsine transformations of the ERs showed no significant effects at all.

Although it was a between-subjects variable, the main effect of familiarity did not reach significance in either the prime or the probe trials. Generally speaking, the more familiar stimuli are, the shorter the responses to them become. The nonsignificance of the main effect of familiarity raises a question about whether the manipulation of familiarity was valid in the present study. To ex- amine this question, we designed a test, Experiment 1B, where familiarity was a within-subjects variable.

\section{EXPERIMENT 1B}

\section{Within-Subjects Replication of Experiment 1A}

\section{Method}

Except for the aspects described below, the method was identical to that of Experiment 1A.

Participants. Twenty-four native Japanese students ( 7 women and 17 men, between 18 and 23 years old) were tested. None of them took part in other experiments of the present study. All participants reported normal or corrected-to-no rmal visual acuity and normal color vision.

Design and Procedure. In Experiment 1B, both familiarity and trial type were manipulated as within-subjects variables. Because the two familiarity conditions were mixed into the same blocks, both the responses to a digit-shaped form and those to its deformation were made by the same corresponding key. Because the test phase was lengthened to 12 blocks of 64 trials, the session lasted about $50 \mathrm{~min}$. Within each block of the test phase, ignored-repetition and control trials of the two familiarity conditions appeared equally often in a random order.

\section{Results}

Negative priming. Mean median probe RTs are shown in Table 1. A 2 (familiarity: high, low) $\times 2$ (trial type: ignored repetition, control) repeated measures ANOVA conducted on the probe RTs revealed significant main effects of both familiarity $\left[F(1,23)=59.67, M S_{\mathrm{e}}=\right.$ $15,772, p<.001]$ and trial type $\left[F(1,23)=13.89, M S_{\mathrm{e}}=\right.$ $3,261, p<.01]$. As in Experiment 1A, the interaction was also significant $\left[F(1,23)=7.12, M S_{\mathrm{e}}=1,024, p<.05\right]$. Panel $B$ of Figure 2 shows the negative priming obtained in Experiment 1B. Individual tests of simple main effects confirmed that significant negative priming occurred in the high-familiarity condition $(18 \mathrm{msec})[F(1,46)=$ $20.93, p<.01]$ and not in the low-familiarity condition $(6 \mathrm{msec})[F(1,46)=1.67]$. That is, larger negative priming again occurred in the high-familiarity condition. The same $2 \times 2$ repeated measures ANOVA conducted on the prime RTs showed that only the main effect of familiarity was significant $\left[F(1,23)=20.52, M S_{\mathrm{e}}=17,496, p<\right.$ $.001]$. Both in the prime and probe trials, shorter RTs were obtained in the high-familiarity condition.

Table 1

Experiments 1A and 1B: Means and Standard Errors of Median Probe Response Times (RTs, in Milliseconds) and Error Rates (ERs, in Percentages) as a Function of Trial Type and Stimulus Familiarity

\begin{tabular}{|c|c|c|c|c|c|c|c|c|}
\hline \multirow[b]{2}{*}{ Trial Type } & \multicolumn{4}{|c|}{ High Familiarity } & \multicolumn{4}{|c|}{ Low Familiarity } \\
\hline & RT & $S E$ & ER & $S E$ & RT & $S E$ & ER & $S E$ \\
\hline \multicolumn{9}{|c|}{ Experiment $1 \mathrm{~A}$} \\
\hline Control & 583 & 12.8 & 3.2 & 0.5 & 631 & 18.2 & 3.2 & 0.5 \\
\hline Ignored repetition & 604 & 12.4 & 4.1 & 0.5 & 633 & 16.9 & 3.3 & 0.6 \\
\hline Difference & $-21^{* *}$ & & -0.9 & & -2 & & -0.1 & \\
\hline \multicolumn{9}{|c|}{ Experiment $1 \mathrm{~B}$} \\
\hline Control & 573 & 9.3 & 3.9 & 0.3 & 605 & 10.0 & 2.8 & 0.3 \\
\hline Ignored repetition & 591 & 9.6 & 4.3 & 0.3 & 611 & 9.9 & 3.0 & 0.4 \\
\hline Difference & $-18^{* *}$ & & -0.4 & & -6 & & -0.2 & \\
\hline
\end{tabular}

${ }^{* *} p<.01$. 


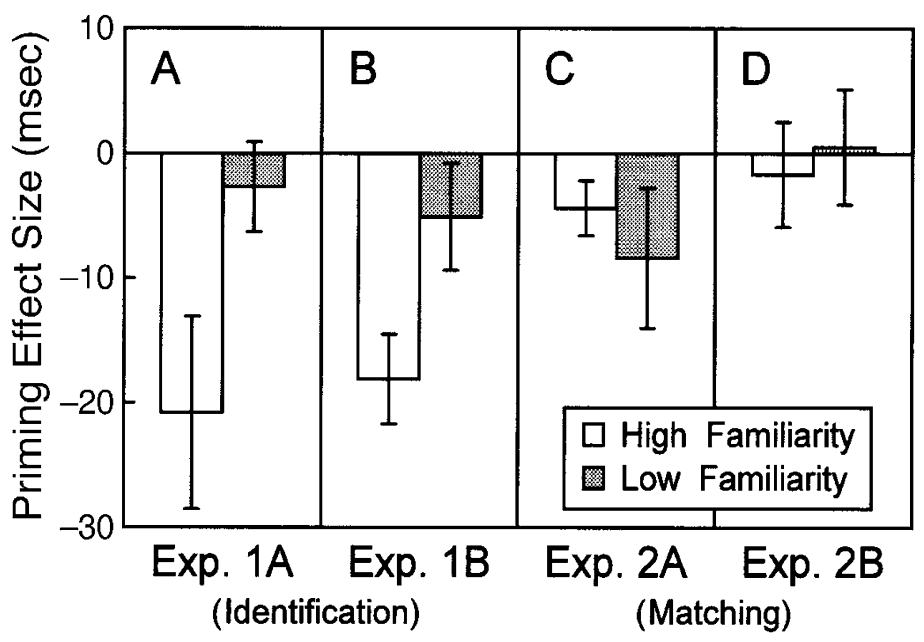

Figure 2. Experiments 1 and 2: Priming scores as a function of stimulus familiarity. Error bars reflect the standard errors of the mean.

Error rates. Mean ERs are also shown in Table 1. According to the same $2 \times 2$ ANOVA done on the arcsine transformations of the ERs, the main effect of familiarity was significant $\left[F(1,23)=23.74, M S_{\mathrm{e}}=0.03, p<\right.$ $.001]$. In contrast to the RT results, smaller ERs were obtained in the low-familiarity condition.

\section{Discussion}

The results of the ER analysis suggest the possibility that the significant main effect of familiarity on RTs was due to a speed-accuracy tradeoff. That is, shorter RTs in the high-familiarity condition may have been obtained at the cost of accuracy. However, there are other possibilities. One is that the participants were so careful to respond in the low-familiarity condition that the RTs became longer and the resulting ERs were smaller than in the high-familiarity condition. Another is that the representations of the familiar distractors were activated more strongly and then produced larger interference than those of the unfamiliar ones, so ERs became larger when the familiarity was high. The latter possibility seems compatible with larger negative priming in the high-familiarity condition. In any case, the ER values were overall so small (less than 5\%) that the RT results may be considered as reliable. Of course, the validity of the manipulation of familiarity in the present study must also be examined in the following experiments.

The results of Experiments 1A and 1B were consistent in that larger negative priming was obtained in the highfamiliarity condition than in the low-familiarity condition. In other words, the results showed a positive correlation between negative priming and stimulus familiarity, similar to the results of Malley and Strayer (1995; Strayer \& Grison, 1999). However, our results are distinct from those of Malley and Strayer (1995; Strayer \& Grison, 1999) in that we used a limited number of stimuli repeatedly in both conditions of familiarity. That is, even when repeatedly presented, the unfamiliar stimuli never produced negative priming in Experiment 1. Although we conducted internal analyses dividing the data into the first and the second halves, no significant difference was found on negative priming between the halves in either Experiment $1 \mathrm{~A}$ or $1 \mathrm{~B}$. These results suggest that stimulus repetition is not sufficient to cause negative priming in the identification task when the stimuli are unfamiliar. Recently, using the word identification task, Grison and Strayer (2001) reported that negative priming was inclined to diminish even with stimulus repetition, when the prime distractors were perceptually degraded. It is likely that the identity representations of less perceptible distractors will not be activated enough to produce negative priming, even though they are presented repeatedly.

On the other hand, Strayer and Grison (1999, Experiment 4) reported the occurrence of negative priming by both familiar and unfamiliar shapes that were repeated in the matching task. Their results suggest that the shape representations of both the familiar and unfamiliar stimuli can be activated strongly if they appear repeatedly. In Experiment 2, we used the same stimuli as in Experiment 1 and examined the effects of stimulus familiarity and repetition on negative priming in the matching task.

\section{EXPERIMENTS 2A AND 2B Matching Task}

The primary objective of Experiment 2 was to examine whether the unfamiliar stimuli would produce larger negative priming than the familiar stimuli in the matching task, as in DeSchepper and Treisman (1996; Treisman \& DeSchepper, 1996). The secondary objective was to examine whether the repeated use of stimuli in the matching task would result in the occurrence of negative priming, as in Strayer and Grison (1999). 
Corresponding to Experiments $1 \mathrm{~A}$ and $1 \mathrm{~B}$, respectively, familiarity was manipulated as a between-subjects variable in Experiment $2 \mathrm{~A}$ and as a within-subjects one in Experiment 2B.

\section{Method}

Participants. Forty-eight native Japanese students were tested, half in Experiment 2A (10 women and 14 men, between 18 and 25 years old) and half in Experiment 2B (4 women and 20 men, between 19 and 23 years old). None of them took part in other experiments of the present study. All participants reported normal or corrected-to-normal visual acuity and normal color vision.

Stimuli and Apparatus. The stimuli and apparatus were identical to those used in Experiment 1.

Task. In Experiment 2, the task was matching of the dual targets by means of a two-alternative forced choice. The participants were instructed to decide whether the two targets had the same image or not (i.e., one was mirror imaged) and to respond with the "C" key if they were the same or the "M" key if they were different, while ignoring the distractors. Answering speed and accuracy were equally emphasized.

Design and Procedure. Except for the change of task requirements from identification to matching, the design and procedure in Experiments 2A and 2B were identical to those in Experiments $1 \mathrm{~A}$ and $1 \mathrm{~B}$, respectively.

\section{Results}

The means of the median probe RTs were first calculated separately for same-same, same-different, differentsame, and different-different response sequences of the prime-probe pairs. ANOVAs including the factors of response difference (same vs. different) in the prime and probe trials were then conducted. In all the matching experiments of the present study, although the main effects of the response difference in the prime and probe trials were significant, these response differences showed no significant interaction with negative priming. Thus, following DeSchepper and Treisman (1996; Treisman \& DeSchepper, 1996), we pooled the four patterns of response sequence in all future analyses of the data from the matching task.

Experiment 2A. Mean median probe RTs and ERs are shown in Table 2. A 2 (familiarity: high, low) $\times 2$ (trial type: ignored repetition, control) mixed ANOVA conducted on the probe RTs revealed that the main effects of familiarity $\left[F(1,22)=5.27, M S_{\mathrm{e}}=46,532, p<\right.$
$.05]$ and trial type $\left[F(1,22)=4.63, M S_{\mathrm{e}}=497, p<.05\right]$ were significant, but the interaction was not $[F(1,22)=$ $\left.0.44, M S_{\mathrm{e}}=47, p>.50\right]$. Panel C of Figure 2 presents the negative priming obtained in Experiment 2A. As in DeSchepper and Treisman (1996; Treisman \& DeSchepper, 1996), the size of negative priming was larger in the lowfamiliarity condition than in the high-familiarity condition. However, individual tests of simple main effects revealed that there were no significant differences between control and ignored-repetition trials in either condition of familiarity - high $(4 \mathrm{msec})[F(1,22)=1.11]$ or low $(8 \mathrm{msec})[F(1,22)=3.96]$. The same $2 \times 2$ mixed ANOVAs conducted on the prime RTs and on the arcsine transformations of the ERs showed that only the main effect of familiarity on the prime RTs was significant $\left[F(1,22)=6.25, M S_{\mathrm{e}}=52,934, p<.05\right]$, and that no other effects reached significant levels.

Experiment 2B. In Experiment 2B, data from 2 participants were excluded from analyses because their overall ER exceeded $10 \%$. Mean median probe RTs and ERs are shown in Table 2. A 2 (familiarity: high, low) $\times 2$ (trial type: ignored repetition, control) repeated measures ANOVA conducted on the probe RTs showed that only the main effect of familiarity was significant $[F(1,21)=$ $\left.94.14, M S_{\mathrm{e}}=72,364, p<.001\right]$, but that the main effect of trial type $\left[F(1,21)=0.04, M S_{\mathrm{e}}=8.59, p>.80\right]$ and the interaction $\left[F(1,21)=0.14, M S_{\mathrm{e}}=26.73, p>.70\right]$ were not. As shown in panel D of Figure 2, negative priming was not observed at all in Experiment 2B. The same $2 \times 2$ repeated measures ANOVAs conducted on the prime RTs and on the arcsine transformations of the ERs showed that the main effect of familiarity on the prime RTs $\left[F(1,21)=92.40, M S_{\mathrm{e}}=71,677, p<.001\right]$, and that on the ERs $\left[F(1,21)=10.53, M S_{\mathrm{e}}=0.04, p<.01\right]$ were significant. Because the ERs were larger in the lowfamiliarity condition (Table 2), this main effect does not indicate a speed-accuracy tradeoff.

\section{Discussion}

The results of Experiment 2 showed that negative priming was very slight or did not occur in the matching task regardless of familiarity, even when the stimuli were repeated. Because the RTs were shorter in the high-

Table 2

Experiments 2A and 2B: Means and Standard Errors of Median Probe Response Times (RTs, in Milliseconds) and Error Rates (ERs, in Percentages) as a Function of Trial Type and Stimulus Familiarity

\begin{tabular}{|c|c|c|c|c|c|c|c|c|}
\hline \multirow[b]{2}{*}{ Trial Type } & \multicolumn{4}{|c|}{ High Familiarity } & \multicolumn{4}{|c|}{ Low Familiarity } \\
\hline & RT & $S E$ & ER & $S E$ & RT & $S E$ & ER & $S E$ \\
\hline \multicolumn{9}{|c|}{ Experiment 2A } \\
\hline Control & 577 & 15.2 & 3.2 & 0.4 & 637 & 23.8 & 4.2 & 0.7 \\
\hline Ignored repetition & 581 & 14.1 & 3.6 & 0.5 & 645 & 22.2 & 3.7 & 0.5 \\
\hline Difference & -4 & & -0.4 & & -8 & & 0.5 & \\
\hline \multicolumn{9}{|c|}{ Experiment $2 \mathrm{~B}$} \\
\hline Control & 582 & 14.4 & 3.1 & 0.4 & 641 & 17.3 & 4.6 & 0.5 \\
\hline Ignored repetition & 584 & 14.3 & 3.2 & 0.4 & 640 & 16.1 & 4.8 & 0.6 \\
\hline Difference & -2 & & -0.1 & & 1 & & -0.4 & \\
\hline
\end{tabular}


familiarity condition in both the prime and probe displays without a speed-accuracy tradeoff, the manipulation of familiarity appears valid in Experiment 2. Why, then, did negative priming fail to occur in this experiment?

One possible reason is that the participants made the same-different judgment on the basis of the stimulus configuration. That is, because the judgment could be made on the basis of whether the stimulus display had a symmetrical configuration, it would have been possible for the participants to neither attend the targets nor ignore the distractors; the use of this strategy could have resulted in the absence of negative priming in the matching task. However, if the participants used this strategy exhaustively, we would have obtained no significant main effect of trial type in Experiment 2A. In any case, the possibility of the symmetry-based strategy in the matching task will be considered in the following experiment.

Another possibility is that the target and distractor stimuli did not overlap spatially. In the shape-matching experiments of the past studies (DeSchepper \& Treisman, 1996; Strayer \& Grison, 1999; Treisman \& DeSchepper, 1996), the target and distractor shapes were presented in the overlapped manner, which very likely caused strong activation of the distractor representations, resulting in negative priming. Indeed, even without overlapping, negative priming has been obtained in past letter-matching experiments in which the distractor letters were flanked with the target ones (Neill, Lissner, \& Beck, 1990; Neill \& Valdes, 1992). However, it is possible that the representations relevant to the letter-matching task, which are presumably the letteridentity representations, could be activated enough only with flanking, whereas the shape representations could not be activated without overlapping.

The results of Experiment 2 are puzzling not only in that negative priming itself failed to occur, but also in that the stimulus familiarity had no effect on negative priming. Why were we unable to reproduce the results of DeSchepper and Treisman (1996; Treisman \& DeSchepper, 1996)? With respect to this issue, we took notice of the peculiarity of stimulus arrangement by DeSchepper and Treisman (1996; Treisman \& DeSchepper, 1996). In Malley and Strayer's (1995; Strayer \& Grison, 1999) experiments, all stimuli of each prime-probe pair were either familiar (i.e., repeated stimuli) or unfamiliar (i.e., novel stimuli). In Experiments 1 and 2 of the present study, we followed this "pure" arrangement of familiarity (Figure 3). In DeSchepper and Treisman's (1996; Treisman \& DeSchepper, 1996) experiments, on the other hand, only the prime distractors and the probe targets of the low-familiarity condition were unfamiliar, whereas the other stimuli were familiar. That is, unfamiliar distractors were mixed with familiar targets in the prime trials, and unfamiliar targets were mixed with familiar distractors in the probe trials. Is it possible that the use of this "mixed" arrangement of familiarity caused the negative correlation between negative priming and familiarity in DeSchepper and Treisman's (1996; Treisman \& DeSchepper, 1996) experiments?

\section{Pure Arrangement Arrangement \\ (Exps. 1-2) \\ (Exps. 3-4)}

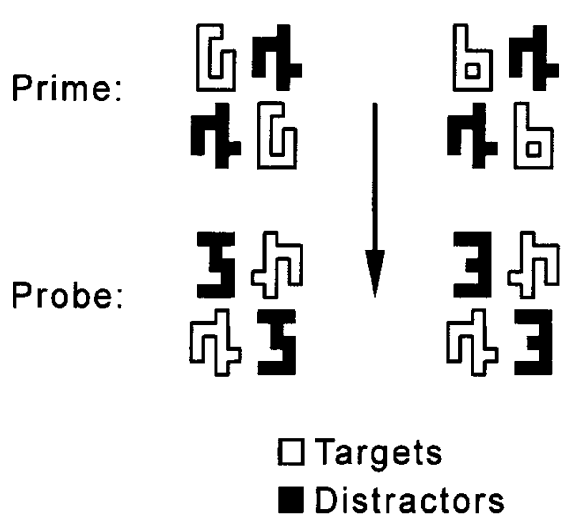

Figure 3. Examples of the two types of stimulus arrangement (pure vs. mixed) in the low-familiarity condition. Whereas all stimuli are unfamiliar under the pure arrangement, only the prime distractors and the probe targets are unfamiliar under the mixed arrangement. Although targets are shown here as unfilled forms and distractors as filled ones, they were actually presented in their assigned colors.

Related to this issue, it has been reported that unfamiliar stimuli "pop out" from the display when surrounded by familiar ones. For example, Johnston, Hawley, Plewe, Elliott, and DeWitt (1990) reported that it was easier to localize an experimentally novel word among repeated words than to localize the repeated one in the same display. Although this finding is well known as novel popout (for a review, see Johnston, Schwarting, \& Hawley, 1996), similar results have been obtained even with nonnovel unfamiliar stimuli (Frith, 1974; Reicher, Snyder, \& Richards, 1976; Richards \& Reicher, 1978; Wang, Cavanagh, \& Green, 1994). For example, Wang et al. (1994) reported a visual search experiment in which only four stimuli (letters and digits) and their mirror images were used repeatedly. In this experiment, the search was efficient when the target was a mirror image (unfamiliar) and the distractors were normal images (familiar), whereas it was inefficient when the assignment was reversed. That is, even when repeatedly presented, an unfamiliar target surrounded by familiar distractors popped out from the display. These findings suggest that the representations of relatively unfamiliar stimuli within the visual field tend to be activated more strongly than those of the surrounding ones, whether they are novel or repeated.

On the basis of this "unfamiliar popout" phenomenon, there may be two ways to explain why DeSchepper and Treisman (1996; Treisman \& DeSchepper, 1996) obtained negative priming by novel shapes with the mixed arrangement. In one explanation, because the prime distractors were less familiar than the targets, they popped 
out and their representations were activated strongly enough to trigger the causal mechanisms of negative priming. In contrast, our failure to obtain negative priming in Experiment 2 was due to the use of the pure arrangement where the unfamiliar stimuli never popped out. The results of Strayer and Grison's (1999) Experiment 5 are consistent with this explanation. In this shape-matching experiment, in which all of the stimuli were novel shapes, negative priming did not occur. Although Strayer and Grison claimed that they were unable to replicate DeSchepper and Treisman's (1996; Treisman \& DeSchepper, 1996) results, they used the pure arrangement rather than the mixed arrangement.

In another explanation, because the novel probe targets in the control condition had never appeared on the preceding prime trials, they might be more novel and so pop out more than those in the ignored-repetition condition. It is possible that the negative priming in the mixed arrangement was due to the speedup from more popout in the control condition than in the ignored-repetition condition. However, if there was an effect of relative novelty in the control probe targets relative to the ignoredrepetition ones, the same effect should have been manifested by novel probe distractors in Strayer and Grison's (1999) Experiment 5. Namely, in the experiment where all stimuli were novel shapes, the probe distractors in the ignored-repetition condition should have popped out because they were more novel than the targets that appeared for the second time. However, though the popout of distractors should have become a cost in selecting targets and caused a delay in responding to them, Strayer and Grison (Experiment 5) have never obtained slower RTs in the ignored-repetition condition than in the control condition. This suggests that the difference of novelty between the control and the ignored-repetition probe targets was insignificant and negligible.

In sum, the former explanation appears more plausible than the latter. In the following experiments, we introduced the mixed arrangement to examine this "unfamiliar popout" explanatory framework.

\section{EXPERIMENTS 3 AND 4 Rearrangement of Stimuli}

In Experiments 3 and 4, the stimulus arrangement was changed from pure (Malley \& Strayer, 1995; Strayer \& Grison, 1999) to mixed (DeSchepper \& Treisman, 1996; Treisman \& DeSchepper, 1996) in both the identification task (Experiment 3 ) and the matching task (Experiment 4). With regard to the matching task, larger negative priming should be observed in the low-familiarity condition than in the high-familiarity condition. On the other hand, we have no clear prediction regarding the identification task. However, if the identity representations of the unfamiliar distractors are activated as strongly as are those of the familiar ones due to unfamiliar popout, large negative priming will be observed in both conditions of familiarity in the identification task.

\section{Method}

Except for the aspects described here, the methods of Experiments 3 and 4 were identical to those of Experiments 1B (identification task) and 2B (matching task), respectively.

Participants. Ninety-two native Japanese students were tested, half in Experiment 3 (21 women and 25 men, between 18 and 27 years old) and half in Experiment 4 (20 women and 26 men, between 20 and 24 years old). None of them took part in other experiments of the present study. All participants reported normal or corrected-to-normal visual acuity and normal color vision.

Design and Procedure. Although the same 2 (familiarity: high, low) $\times 2$ (trial type: ignored repetition, control) within-subjects design was used as in Experiments $1 \mathrm{~B}$ and $2 \mathrm{~B}$, there was a change in the arrangement of stimuli. That is, in the low-familiarity condition, only the prime distractors and probe targets were chosen from the unfamiliar set; the prime targets and probe distractors were from the familiar set (Figure 3). In the high-familiarity condition, on the other hand, all stimuli were chosen from the familiar set.

\section{Results and Discussion}

Experiment 3: Identification task. In Experiment 3, data from 1 participant were excluded from the analyses because the overall ER exceeded $10 \%$. Mean median probe RTs and ERs are shown in Table 3. A 2 (familiarity: high, low) $\times 2$ (trial type: ignored repetition, control) repeated measures ANOVA conducted on the probe RTs revealed that the main effects of familiarity $\left[F(1,44)=77.02, M S_{\mathrm{e}}=\right.$ $63,431, p<.001]$ and trial type $\left[F(1,44)=37.68, M S_{\mathrm{e}}=\right.$ $6,372, p<.001]$ were significant, but that the interaction was not $\left[F(1,44)=0.26, M S_{\mathrm{e}}=56, p>.60\right]$. Panel A of Figure 4 presents the negative priming obtained in Experiment 3. Individual tests of simple main effects showed that significant negative priming occurred in both familiarity conditions-high $(11 \mathrm{msec})[F(1,88)=13.64, p<.01]$ and low $(13 \mathrm{msec})[F(1,88)=19.84, p<.01]$. That is, under the mixed arrangement, negative priming was newly observed in the low-familiarity condition. The same ANOVAs conducted on the prime RTs and the arcsine transformations of the ERs showed no significant effects.

Experiment 4: Matching task. Mean median probe RTs and ERs are shown in Table 3. A 2 (familiarity: high, low) $\times 2$ (trial type: ignored repetition, control) repeated measures ANOVA was conducted on the probe RTs. The main effects of familiarity $[F(1,45)=114.29$, $\left.M S_{\mathrm{e}}=186,150, p<.001\right]$ and trial type $[F(1,45)=9.26$, $\left.M S_{\mathrm{e}}=2,494, p<.01\right]$, and the interaction $[F(1,45)=$ $\left.4.54, M S_{\mathrm{e}}=750, p<.05\right]$, were significant. The significance of the interaction suggests that negative priming depended upon stimulus familiarity. Panel B of Figure 4 presents the negative priming obtained in Experiment 4. Individual tests of simple main effects revealed that significant negative priming occurred in the low-familiarity condition $(12 \mathrm{msec})[F(1,90)=13.76, p<.01]$, but not in the high-familiarity condition $(3 \mathrm{msec})[F(1,90)=$ $1.17, p>.05]$. As in Experiment 3, negative priming in the low-familiarity condition was newly observed by the use of the mixed arrangement. The occurrence of reliable negative priming in Experiment 4 indicates that the absence of negative priming in Experiment 2 was not due to the symmetry-based strategy for the matching task in 
Table 3

Experiments 3 and 4: Means and Standard Errors of Median Probe

Response Times (RTs, in Milliseconds) and Error Rates (ERs, in

Percentages) as a Function of Trial Type and Stimulus Familiarity

\begin{tabular}{|c|c|c|c|c|c|c|c|c|}
\hline \multirow[b]{2}{*}{ Trial Type } & \multicolumn{4}{|c|}{ High Familiarity } & \multicolumn{4}{|c|}{ Low Familiarity } \\
\hline & RT & $S E$ & ER & $S E$ & RT & $S E$ & ER & $S E$ \\
\hline \multicolumn{9}{|c|}{ Experiment 3} \\
\hline Control & 587 & 10.9 & 4.1 & 0.2 & 623 & 12.5 & 3.9 & 0.3 \\
\hline Ignored repetition & 598 & 9.9 & 3.8 & 0.3 & 636 & 13.4 & 3.9 & 0.3 \\
\hline Difference & $-11^{* *}$ & & 0.3 & & $-13^{* *}$ & & 0.0 & \\
\hline \multicolumn{9}{|c|}{ Experiment 4} \\
\hline Control & 576 & 7.8 & 3.0 & 0.3 & 635 & 10.7 & 4.8 & 0.4 \\
\hline Ignored repetition & 579 & 8.0 & 3.5 & 0.3 & 647 & 12.2 & 4.4 & 0.4 \\
\hline Difference & -3 & & -0.5 & & $-12^{* *}$ & & 0.4 & \\
\hline
\end{tabular}

${ }^{* * *} p<.01$

the present study. Moreover, the results showed that larger negative priming was produced by less familiar stimuli, analogous to the results of DeSchepper and Treisman (1996; Treisman \& DeSchepper, 1996).

According to the same $2 \times 2$ ANOVA conducted on the ERs, the main effect of familiarity was significant $\left[F(1,45)=21.78, M S_{\mathrm{e}}=0.06, p<.001\right]$. Since the ERs were larger in the low-familiarity condition (Table 3 ), this main effect does not indicate a speed-accuracy tradeoff. Besides, in the same ANOVA done on the prime RTs, the main effect of familiarity was significant $[F(1,45)=$ $\left.26.59, M S_{\mathrm{e}}=5,082, p<.001\right]$. The mean prime RTs (in milliseconds) and standard errors (in parentheses) for control and ignored-repetition trials were 573 (7.4) and 572 (7.3) in the high-familiarity condition, and 581 (6.9) and 585 (8.2) in the low-familiarity condition, respectively. In the low-familiarity prime displays, only the distractors were unfamiliar shapes, whereas the targets were familiar ones, as in the high-familiarity primes (Figure 3). The longer RTs for the low-familiarity primes probably reflected the popout of the unfamiliar distractors, which caused interference in the prime trials and significant negative priming in the probe trials. ${ }^{2}$

Interestingly, when the mixed arrangement was used, negative priming occurred anew in the low-familiarity condition of both Experiments 3 and 4. In the prime trials under the mixed arrangement, the unfamiliar distractors must have popped out because they were presented with the familiar targets (see Johnston et al., 1990; Reicher et al., 1976; Wang et al., 1994). It seems that the representations of the unfamiliar distractors were activated so strongly that negative priming occurred in both tasks. Does this suggest that the identification and the matching tasks used the same relevant representations? The answer is probably no. If the task-relevant representations were common to the two tasks, the same results should have been obtained in the two tasks universally. The different pattern of negative priming due to the task difference throughout the present study indicates that the task-relevant representations were differentiated by the behavioral goals (Tipper et al., 1994). It is more likely that the activation of the high-level representations of the distractors is dependent on the activation of their lowlevel representations (see also Grison \& Strayer, 2001). The occurrence of negative priming in the low-familiarity condition of Experiment 3 (the identification task) may have reflected the strong activation of the identity representations of the distractors following that of their shape representations, which caused negative priming in Experiment 4 (the matching task).

\section{GENERAL DISCUSSION}

The goal of the present study was to resolve the discrepancy concerning the relation between negative priming and stimulus familiarity (Malley \& Strayer, 1995; Strayer \& Grison, 1999; DeSchepper \& Treisman, 1996; Treisman \& DeSchepper, 1996). Toward this goal, we evaluated the following factors in past studies: (1) the task requirement that determines the behavioral goal (identification vs. matching) and (2) the stimulus arrangement in the low-familiarity condition (pure vs. mixed).

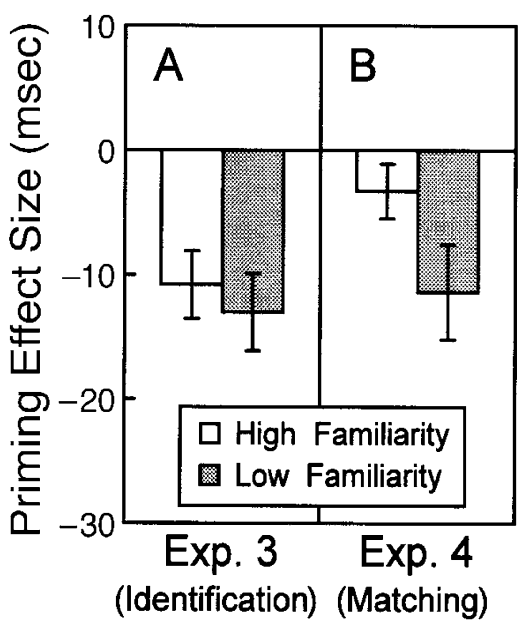

Figure 4. Experiments 3 and 4: Priming scores as a function of stimulus familiarity. Error bars reflect the standard errors of the mean. 
Corresponding to the combinations of these factors $(2 \times$ 2 ), four experiments were conducted using identical stimulus sets. In Experiment 1, we used an identification task with a pure arrangement and obtained a positive correlation between negative priming and stimulus familiarity, similar to the results of Malley and Strayer (1995; Strayer \& Grison, 1999). On the other hand, in Experiment 4, we used a matching task with a mixed arrangement and obtained a negative correlation, similar to the results of DeSchepper and Treisman (1996; Treisman \& DeSchepper, 1996). That is, using the identical stimuli, we were able to obtain opposite results analogous to the past discrepant results. Our results suggest that the discrepancy in the past studies was caused by the combination of the factors of task requirement and stimulus arrangement in the low-familiarity condition.

Although the present study obtained results similar to those of past opposing studies (DeSchepper \& Treisman, 1996; Malley \& Strayer, 1995; Strayer \& Grison, 1999; Treisman \& DeSchepper, 1996), our results are distinct from them regarding the effect of stimulus repetition. In Experiment 1 (the identification task with the pure arrangement), the repeated stimuli did not produce negative priming when they were unfamiliar shapes. According to the activation hypothesis developed by Malley and Strayer (1995; Strayer \& Grison, 1999), repetition of stimuli leads to the activation of their stored representations, which triggers the inhibitory mechanisms of attention and results in the occurrence of negative priming. The results of Experiment 1 suggest that when both the target and distractor shapes were unfamiliar, the identity representations of the latter would not be activated enough to produce negative priming regardless of repetition. Besides, in Experiment 2 (the matching task with the pure arrangement), the repeated shapes never produced negative priming regardless of whether they were familiar or unfamiliar, contrary to Strayer and Grison's Experiment 4. A crucial difference between the two experiments appears to be that the target and distractor shapes were spatially overlapped in Strayer and Grison's Experiment 4, whereas they were not in our Experiment 2. It is likely that unless the target and distractor shapes are overlapped and their segmentation is difficult, the shape representations of the distractors will not be activated sufficiently to cause negative priming irrespective of their repetition.

On the other hand, in our Experiment 4 (the matching task with the mixed arrangement), even the nonoverlapped distractors produced negative priming when they were unfamiliar and mixed with the familiar targets. As previously discussed, negative priming in this case seems to have reflected the popout of unfamiliar distractors in the prime displays. It has been suggested that relatively unfamiliar stimuli within the visual field tend to pop out (e.g., Johnston et al., 1990; Reicher et al., 1976; Wang et al., 1994). It is likely that because the relatively unfamiliar distractors popped out, their representations were activated so strongly that negative priming occurred in Experiment 4 even without overlapping. The occurrence of the popout of unfamiliar prime distractors is plausible in that the prime RTs were longer in the low-familiarity condition than in the high-familiarity condition. Within this unfamiliar popout framework, it can be explained why DeSchepper and Treisman (1996; Treisman \& DeSchepper, 1996) obtained negative priming by novel shapes with the mixed arrangement, whereas Strayer and Grison (1999, Experiment 5) failed to obtain this effect with the pure arrangement in the matching task.

More recently, Loula, Kourtzi, and Shiffrar (2000) reported a series of shape-matching experiments in which novel shapes produced negative priming even with the pure arrangement. Although the results of Loula et al. appear inconsistent with those of Strayer and Grison (1999), the procedure of Loula et al. was unusual in that the participants were not required to respond to the prime displays, which were presented for a rather long duration $(1,000$ or $1,500 \mathrm{msec})$. When the duration of stimuli is long, a large amount of attention can be allocated to them. There is a possibility that more attention to the distractors due to their long duration caused stronger activation of their representations, so that Loula et al. could obtain negative priming despite their use of the pure arrangement. Regarding the effect of attentional allocation, Houghton, Tipper, Weaver, and Shore (1996) and MacDonald, Joordens, and Seergobin (1999) also reported results suggesting that more attention to the distractors led to larger negative priming. In future research, the effects of attentional allocation as well as unfamiliar popout on negative priming should be examined more precisely.

Finally, regarding the theoretical controversy about negative priming, the present results provide no decisive evidence, because it is suggested that the results of both Malley and Strayer (1995; Strayer \& Grison, 1999) and DeSchepper and Treisman (1996; Treisman \& DeSchepper, 1996) are replicable. The former provide evidence that supports the distractor inhibition theories (e.g., Houghton \& Tipper, 1994; Malley \& Strayer, 1995; Neill, 1977; Neumann \& DeSchepper, 1992; Tipper, 1985), whereas the latter provide evidence favorable to the episodic retrieval theory (Neill et al., 1992). The most essential difference between the two theories appears to be that different types of representations are assumed to be associated with negative priming. That is, distractor inhibition theories assume that the reactivation of preexisting representations of the distractors triggers the inhibitory mechanisms of attention: These representations are not specific to individual appearances of the stimuli, but reflect more abstract information about them. On the other hand, the episodic retrieval theory assumes the encoding and retrieval mechanisms of episodic representations that represent particular ex periences about the stimuli. Then, with the behavioral goal hypothesis of Tipper et al. (1994) in mind, we can suppose that the inhibitory mechanisms of attention will work when the abstract representations are relevant to the current task, whereas the memory retrieval mechanisms will work when the episodic representations are relevant. Recently, it has been proposed (Kane, May, 
Hasher, Rahhal, \& Stoltzfus, 1997; May et al., 1995; Milliken, Joordens, Merikle, \& Seiffert, 1998) that both attention and memory mechanisms are involved in negative priming. Although the relation between these mechanisms and the present results is not yet clear, it will be helpful for future research to consider what type of representation (abstract or episodic) is relevant to the current task and associated with negative priming.

\section{REFERENCES}

Dalrymple-Alford, E. C., \& Budayr, B. (1966). Examination of some aspects of the Stroop color-word test. Perceptual \& Motor Skills, 23, 1211-1214.

DeSchepper, B., \& Treisman, A. (1996). Visual memory for novel shapes: Implicit coding without attention. Journal of Experimental Psychology: Learning, Memory, \& Cognition, 22, 27-47.

Fox, E. (1995). Negative priming from ignored distractors in visual selection: A review. Psychonomic Bulletin \& Review, 2, 145-173.

FriTh, U. (1974). A curious effect with reversed letters explained by a theory of schema. Perception \& Psychophysics, 16, 113-116.

Grison, S., \& Strayer, D. L. (2001). Negative priming and perceptual fluency: More than what meets the eye. Perception \& Psychophysics, 63, 1063-1071.

Houghton, G., \& Tipper, S. P. (1994). A model of inhibitory mechanisms in selective attention. In D. Dagenbach \& T. H. Carr (Eds.), Inhibitory processes in attention, memory, and language (pp. 53-112). San Diego: Academic Press.

Houghton, G., Tipper, S. P., Weaver, B., \& Shore, D. I. (1996). Inhibition and interference in selective attention: Some tests of a neural network model. Visual Cognition, 3, 119-164.

Johnston, W. A., Hawley, K. J., Plewe, S. H., Elliott, J. M. G., \& DeWitT, M. J. (1990). Attention capture by novel stimuli. Journal of Experimental Psychology: General, 119, 397-411.

Johnston, W. A., Schwarting, I. S., \& Hawley, K. J. (1996). Novel pop-out, perceptual inhibition, and the stability-plasticity dilemma. In A. F. Kramer, M. G. H. Coles, \& G. D. Logan (Eds.), Converging operations in the study of visual selective attention (pp. 315-335) Washington, DC: American Psychological Association.

Kane, M. J., May, C. P., Hasher, L., Rahhal, T., \& Stoltzfus, E. R. (1997). Dual mechanisms of negative priming. Journal of Experimental Psychology: Human Perception \& Performance, 23, 632-650.

Loula, F., KourtZI, Z, \& Shiffrar, M. (2000). Surface segmentation cues influence negative priming for novel and familiar shapes. Journal of Experimental Psychology: Learning, Memory, \& Cognition, 26, 929-944.

MacDonald, P. A., Joordens, S., \& Seergobin, K. N. (1999). Negative priming effects that are bigger than a breadbox: Attention to distractors does not eliminate negative priming, it enhances it. Memory \& Cognition, 27, 197-207.

Malley, G. B., \& Strayer, D. L. (1995). Effect of stimulus repetition on positive and negative identity priming. Perception \& Psychophysics, 57, 657-667.

May, C. P., Kane, M. J., \& Hasher, L. (1995). Determinants of negative priming. Psychological Bulletin, 118, 35-54.

Milliken, B., Joordens, S., Merikle, P. M., \& Seiffert, A. E. (1998). Selective attention: A reevaluation of the implications of negative priming. Psychological Review, 105, 203-229.

Milliken, B., Tipper, S. P., \& Weaver, B. (1994). Negative priming in a spatial localization task: Feature mismatching and distractor inhibition. Journal of Experimental Psychology: Human Perception \& Performance, 20, 624-646.

NeILL, W. T. (1977). Inhibitory and facilitatory processes in selective attention. Journal of Experimental Psychology: Human Perception \& Performance, 3, 444-450.

NeILL, W. T., LissNer, L. S., \& BeCK, J. L. (1990). Negative priming in same-different matching: Further evidence for a central locus of inhibition. Perception \& Psychophysics, 48, 398-400.

NeILl, W. T., \& VALDES, L. A. (1992). Persistence of negative priming:
Steady state or decay? Journal of Experimental Psychology: Learning, Memory, \& Cognition, 18, 565-576.

NeILl, W. T., \& VAldes, L. A. (1996). Facilitatory and inhibitory aspects of attention. In A. F. Kramer, M. G. H. Coles, \& G. D. Logan (Eds.), Converging operations in the study of visual selective attention (pp. 77-106). Washington, DC: American Psychological Association.

Neill, W. T., Valdes, L. A., \& Terry, K. M. (1995). Selective attention and the inhibitory control of cognition. In F. N. Dempster \& C. J. Brainerd (Eds.), Interference and inhibition in cognition (pp. 207261). San Diego: Academic Press.

Neill, W. T., Valdes, L. A., Terry, K. M., \& Gorfein, D. S. (1992). Persistence of negative priming: II. Evidence for episodic trace retrieval. Journal of Experimental Psychology: Learning, Memory, \& Cognition, 18, 993-1000.

Neumann, E., \& DeSchepper, B. G. (1992). An inhibition-based fan effect: Evidence for an active suppression mechanism in selective attention. Canadian Journal of Psychology, 46, 1-40.

Reicher, G. M., SNYder, C. R. R., \& Richards, J. T. (1976). Familiarity of background characters in visual scanning. Journal of Experimental Psychology: Human Perception \& Performance, 2, 522-530.

Richards, J. T., \& ReIcher, G. M. (1978). The effect of background familiarity in visual search: An analysis of underlying factors. Perception \& Psychophysics, 23, 499-505.

Strayer, D. L., \& Grison, S. (1999). Negative identity priming is contingent on stimulus repetition. Journal of Experimental Psychology: Human Perception \& Performance, 25, 24-38.

TIPPER, S. P. (1985). The negative priming effect: Inhibitory priming by ignored objects. Quarterly Journal of Experimental Psychology, 37A, 571-590.

TIPPER, S. P. (2001). Does negative priming reflect inhibitory mechanisms? A review and integration of conflicting views. Quarterly Journal of Experimental Psychology, 54A, 321-343.

Tipper, S. P., Weaver, B., \& Houghton, G. (1994). Behavioural goals determine inhibitory mechanisms of selective attention. Quarterly Journal of Experimental Psychology, 47A, 809-840.

Treisman, A., \& DeSchepper, B. (1996). Object tokens, attention, and visual memory. In T. Inui \& J. L. McClelland (Eds.), Attention and performance XVI: Information integration in perception and communication (pp. 15-46). Cambridge, MA: MIT Press.

Wang, Q., Cavanagh, P., \& Green, M. (1994). Familiarity and pop-out in visual search. Perception \& Psychophysics, 56, 495-500.

\section{NOTES}

1. Although the difference between the same and different displays had no correspondence to responses in the identification task, we examined whether the difference of displays had any influence on negative priming by the same method as is usually applied in matching studies (e.g., DeSchepper \& Treisman, 1996; Neill et al., 1990). Namely, we first calculated the means of the median probe response times (RTs) separately for same-same, same-different, different-same, and differentdifferent display sequences of the prime-probe pairs, and then conducted analyses of variance (ANOVAs) including the factor of display difference (same vs. different) in the prime and probe trials. Throughout the identification experiments of the present study, although the main effect of display difference in the probe trials was always significant (i.e., shorter RTs for the same probe displays), this effect showed no significant interaction with negative priming. Therefore, we pooled the four patterns of display sequence in all future analyses of the data from the identification task.

2 . The relation between distractor interference and negative priming has been controversial (see Fox, 1995; Neill \& Valdes, 1996; Neill et al., 1995). Although it is outside our current scope to deal with this issue, the results (a positive correlation between them) appear in favor of the view that the mechanisms of negative priming function reactively to protect relevant information processing from distractor interference (Neill \& Valdes, 1996; Neill et al., 1995).

(Manuscript received July 17, 2000; revision accepted for publication October 15, 2002.) 